\title{
Agroecology: A New Research and Development Paradigm for World Agriculture
}

\author{
MIGUEL A. ALTIERI \\ Division of Biological Control, University of California, Berkeley, 1050 San Pablo Avenue, \\ Albany, CA 94706 (U.S.A.)
}

(Accepted for publication 19 April 1989)

\section{ABSTRACT}

Altieri, M.A., 1989. Agroecology: a new research and development paradigm for world agriculture. Agric. Ecosystems Environ., 27: 37-46.

In its several conceptions, agroecology has emerged as a scientific approach used to study, diagnose and propose alternative low-input management of agroecosystems. Solving the sustainability problem of agriculture is the primary aim of agroecology. It is maintained here, however, that simply focusing on the technological aspects of the problem, even though promoted technologies are low-input, obscures the fundamental problems that lie behind the technology-induced environmental crisis and rural poverty affecting the agricultural regions of the world. Agroecology can provide the ecological guidelines to point technological development in the right direction, but in the process, technological issues must assume their corresponding role within a strategy of rural development that incorporates social and economic problems.

\section{INTRODUCTION}

During the last two decades, interest in sustainable agriculture has grown to worldwide proportions, with various sectors of society slowly realizing that resource scarcity, environmental degradation, population growth, uncontrolled economic growth and/or stagnation, social marginalization, etc. are seriously threatening the long-term limits of agricultural expansion. Although these problems affect most regions in the world, their intensity or perceived importance differs in each area, as does the motivation behind the pursuit of sustainable agricultural development. Clearly, in industrialized countries (ICs) a major factor has been the need to deal with the consequences of technology induced environmental degradation resulting from a sort of "development oversaturation". Conversely, in developing countries (LDCs), historically speaking, "development" has not reached the vast population of resource-poor farmers. Therefore, there is a great need to match agricultural development with the needs of this sector of society. 
In both cases, the development of an "appropriate technology" capable of translating productive potentials into sustainable livelihood for all has been a central idea. A number of agricultural research and development schemes (i.e. farming systems research and extension, agroecosystem analysis and development, etc.) have been suggested in order to reach this goal. Most of these approaches: (1) emphasize a systems framework of analysis; (2) focus on both biophysical and socio-economic constraints on production; (3) utilize the agroecosystem or the region as a unit of analysis. These approaches have improved diagnostic methodologies and have also introduced new criteria (i.e. sustainability, equitability, stability, etc.) to evaluate the performance of agricultural systems (Conway, 1986).

In its various conceptions, agroecology has been proposed as a new scientific discipline that defines, classifies and studies agricultural systems from an ecological and socio-economic perspective (Altieri, 1987). In addition to providing a methodology to diagnose the "health" of agricultural systems, agroecology should delineate the ecological principles necessary to develop sustainable production systems.

Undoubtedly these new agroecological approaches have allowed us to understand better, in a more fully integrated manner, the various factors that govern agricultural productivity and to develop new technological avenues to overcome these factors in a more environmentally sound manner (Lowrence et al., 1984). However, by perceiving the problem of sustainability solely as a technological problem of production, most agroecological approaches are restricted in their ability to understand and address the fundamental reasons why agricultural systems become non-sustainable. Clearly, new sustainable agroecosystems cannot be implemented without modifying the socio-economic determinants that govern what is produced, how it is produced, and for whom it is produced. Agroecology should deal with technological issues in such a way that these assume their corresponding roles within a political agenda that incorporates social and economic factions in its development strategy. Only policies and actions derived from the implementation of such a strategy can confront the structural and economic factors that determine the agriculturalenvironmental crisis in the ICs and rural poverty in the LDCs. It is therefore the intention of this paper to explore ways in which agroecology can be utilized within a broader rural development agenda that, while improving the technical capabilities of farmers and conserving their resource base, also takes into consideration the impinging social, economic and political constraints.

\section{AGROECOLOGY IN THE INDUSTRIALIZED COUNTRIES}

In the U.S., the environmental movement has contributed a great deal to agroecology. This movement is primarily concerned with the impacts of toxic substances, especially pesticides, on the environment. In the early 1970s, part 
of the response to these problems was the development of integrated pest management (IPM) which sought to modify radically the philosophy of crop protection, de-emphasizing the control aspect in favor of a management orientation which entailed a deeper understanding of insect and crop ecology and relied on the use of several complementary tactics (Rabb and Guthrie, 1970). The earlier papers on the topic were a challenge to agricultural researchers to rethink their chemically based approach, urging them to move toward integrated systems in which pesticides would be just one more element, and used only in emergency situations (Metcalf and Luckman, 1975). When the ecological foundations of IPM were being formulated by its advocates, a major critical concept was that modern agroecosystems resembled immature simplified ecosystems and therefore lacked the ability to regulate pest populations. Many researchers then visualized the diversification of agricultural systems as a desirable goal (Southwood and Way, 1970; Price and Waldbauer, 1975; Pimentel and Goodman, 1978). In practice, however, this never happened, because management proposals that deviated from the prevailing monocultural practice did not fit the current management schemes, nor the economic structure that historically propelled U.S. agriculture into world pre-eminence. The lack of adoption of integrated practices in California, such as strip cropping in alfalfa to control lygus bug, or using blackberries as parasite harborage for grapeleafhopper in vineyards (both of which systems demonstrated the potential to reduce pest populations) are two cases in point (Altieri and Letourneau, 1982).

Thus in the U.S. and in general in the developed world, the novel ideas of IPM had minimal impact on the structure of agriculture; in fact, the concept was slowly absorbed by the current system to accommodate the interests of profit-oriented corporations and/or large-scale farmers attracted by the potential of minimizing the cost of production (although welcoming accrued environmental benefits) to result from more regimented pesticide applications (van den Bosch, 1980). In this context, IPM in the 1980s came to signify "integrated pesticide management," thus perpetuating the use of toxic substances (although admittedly in a more regulated manner).

In the 1970s when oil prices rocketed, the dependence of U.S. agriculture on purchased input and fossil-fuel energy became evident, prompting more research into energy efficient cropping systems and technologies (Pimentel and Pimentel, 1974). At the time, a number of practices used by organic agriculturalists (i.e. crop rotations, organic amendments, cultural pest control, etc.) were seen, even by conventional researchers, as viable possibilities to reduce energy use in agriculture (USDA, 1980). This interest in energy efficiency was later broadened to include aspects of natural resource conservation and environmental quality through the promotion of low-input agricultural practices, embraced under what today we call sustainable agriculture (Douglass, 1984).

Thus, in the 1980s, a number of individuals at universities, agricultural research centers and non-profit organizations initiated research and education 
activities aimed at the development of land restorative, environmentally sound, economically viable and socially acceptable agricultural systems. Of primary importance to these projects is the desire to develop agricultural systems that sustain production in the long run without degrading the resource base. Thus the range of options that potentially meet these goals includes a variety of lowinput technologies that improve soil fertility and conservation, maximize recycling, enhance biological pest control, diversify production, etc. (Fig. 1). Inherent to these projects is the conviction that as long as the proposed systems benefit the environment and are profitable, sustainability will eventually be achieved and all humankind will benefit. Thus, sustainable agriculture technologies are seen as relatively neutral, and the question of which segments of society benefit is of no concern, since it is assumed that what is good for the environment is good for society at large. This attitude can prove problematic and dangerous for three main reasons.

(1) By failing to see capital relations of production as a determinant of how and to whom technology is delivered, technology (whether sustainable or not) will continue to be delivered preferentially to the class holding the capital and political power (Levins, 1973).

(2) By focusing on low-input technologies as a main component of sustainable agricultural development, a number of biotechnologies (which are clearly not scale-neutral nor capital-neutral) will be proposed as viable options, enhancing farmers' dependence on the private sector.

(3) Corporate and large-scale farmers will rapidly shift to alternative methods because there is a good prospect for monetary gain (i.e. low inputs reduce the costs of production), potentially displacing (because of economies of scale) a number of small farmers committed to sustainable agriculture not only for financial reasons, but for ecological and moral ones. More and more small farmers will shift to specialty crops oriented to elite markets, as a way to exploit economic opportunities, in order to survive in the capitalist-oriented economy. Such trends are already occurring in California.

It is therefore crucial that scientists involved in the search for sustainable agricultural technologies be concerned about who will ultimately benefit from them. This requires recognizing that political determinants should be considered at the point when basic scientific questions are asked and not just at the moment when technologies are delivered to society (van der Meer, unpublished data). Thus, what is produced, how it is produced and for whom it is produced are key questions that need to be taken into consideration if a socially equitable agriculture is to emerge. When such questions are examined, issues of land tenure, labor, appropriate technology, public health, research policy etc. unavoidably arise. Examination of these questions should proceed even at the expense of recognizing that political systems, other than the capitalist model, might represent the best hope of changing the structural basis that is perpetuating the environmental crisis of modern agriculture. 


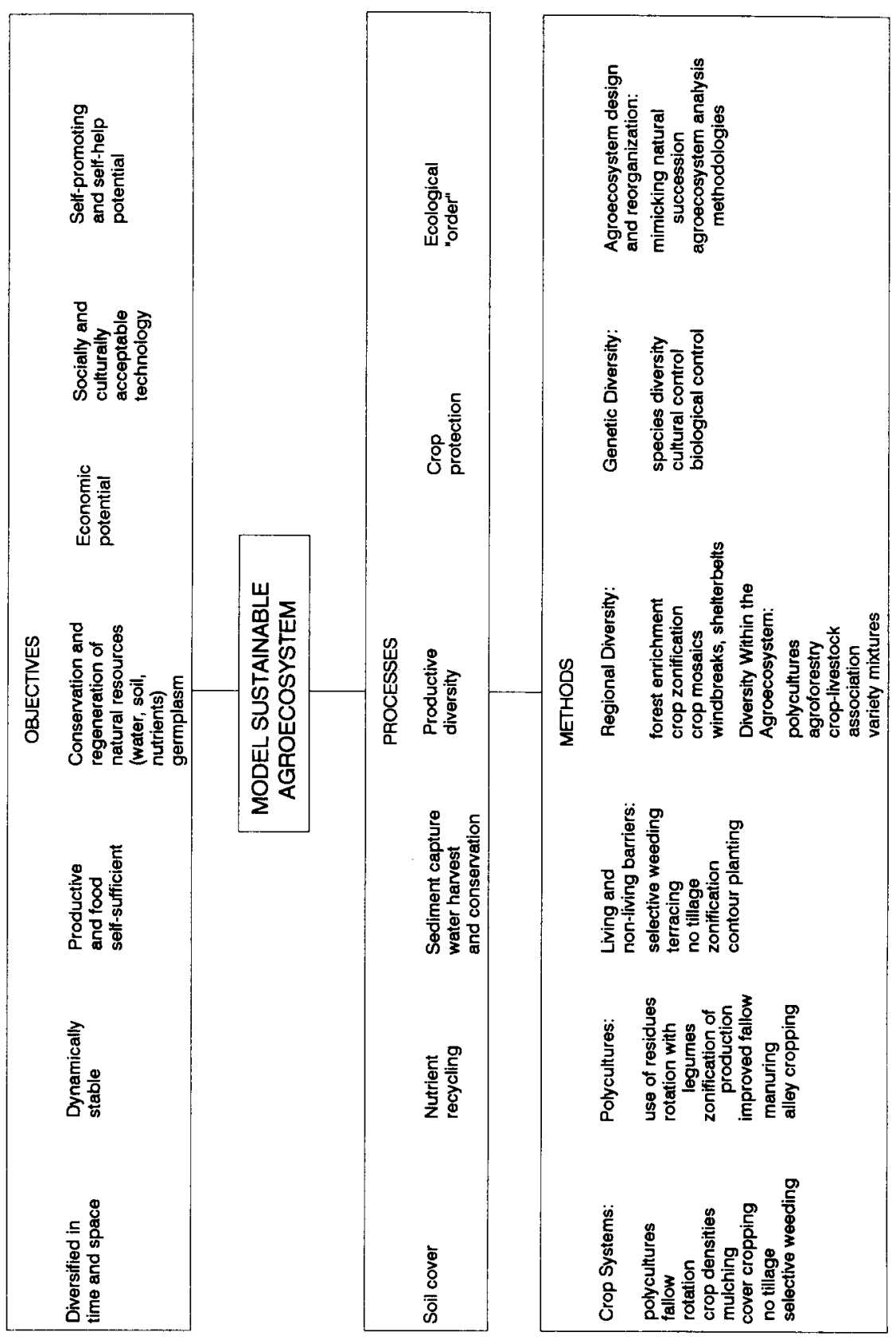

Fig. 1. Model of a sustainable agroecosystem. 
The problem of hunger and rural poverty in the developing countries has been perceived fundamentally as a problem of production. Attempts to solve the problem of hunger have focused on developing a system by which "low productivity" subsistence-oriented agriculture could be transformed into "highproductivity" commercial, cash crop-oriented agriculture (Chambers and Ghildyal, 1985). Thus attempts at modernizing Third World agriculture started after World War II when land- and labor-saving technologies were promoted. The diffusion of these technologies was related to agroclimatic and socioeconomic conditions, and was introduced in a pattern of sequential cycles. After an extensive initial period in which agronomic practices were the most important technology, mechanization became the dominant technology in the early 1970 s. Next came the dissemination of improved seeds, especially hybrids. Pesticides and fertilizers represent the last of this technological cycle, which has still to reach its inflection point (de Janvry et al., 1987). Three aspects characterize this process of technological diffusion.

(1) Technological change concentrated mainly in temperate and subtropical areas where conditions are similar to those in the industrial countries where the technology was generated.

(2) Many LDCs have become net importers of chemical inputs and agricultural machinery, increasing government expenditures and exacerbating technological dependence. For example, between 1980 and 1984 Latin America imported about 430 million dollars worth of pesticides, used about 6.5 million tons of fertilizers, and had well over 850000 tractors (Ortega, 1986).

(3) Technological change has mainly benefited the production of export and/ or commercial crops produced primarily in the large farm sector, marginally impacting productivity of food crops, which are largely grown by the peasant sector (Ortega, 1986). In areas where conversion from subsistence to cash agricultural economy progressively occurred, a number of ecological and social problems became evident: loss of food self-sufficiency, genetic erosion, loss of traditional farming knowledge, permanence of rural poverty, etc. (Toledo et al., 1985).

A fifth technological diffusion cycle will soon be initiated in LDCs as biotechnological research (mainly promoted by the private sector), starts offering innovations. Recent discoveries in biotechnology are starting to challenge countries to reassess their technological development. Since biotechnological research and development is mainly concerned with specialty and industrial crops, and/or with crops tailored to specific input needs, it is presumed that, as in the case of the Green Revolution, it will only benefit resource-rich farmers who can afford to adopt biotechnological products, thus again by-passing resource-poor farmers, especially those confined to rainfed, hillside areas (Hobbelink, 1987). Biotechnology can speed up the technological treadmill, in- 
crease production and put downward pressure on prices, which may cause peasants to become increasingly marginal producers without assistance (de Janvry et al., 1987) unless the public sector, universities and non-government organizations (NGOs) undertake a major research effort tailored to meet peasant needs and circumstances.

A major dilemma facing agroecologists is to determine how to increase agricultural productivity further in a way that the rural poor can significantly benefit (Wolf, 1986). The challenge, however, is to realize that this is not really possible without facilitating the access of peasants to land, water and other natural resources, as well as to equitable credit, markets, appropriate technologies, etc. Only political change resulting from progressive government policy or strong community-based actions can secure farmers' control over the institutions that govern access to resources and inputs. Agroecology can only hope to provide the ecological basis to manage the resources once available to the rural poor. In other words, as an agricultural development approach, agroecology cannot confront the structural and economic factors that are the cause of rural poverty. As emphasized above, this will require a much broader development approach that, among other things, will have to face the question of social organization of the peasantry effectively.

Rather than creating or transferring new technology, the fundamental idea of agroecology is to encourage an attitude or development of criteria toward the technological process, which will allow farmers to discriminate, select and adopt new technologies, and also which confirms the validity of those processes that originate within their own social group (Richards, 1985). In Latin America there are a number of NGOs that have taken this more pedagogical approach, creating programs that emphasize research, education, technical assistance and credit provision activities aimed at the development of peasant agriculture. Many of these groups have demonstrated a unique ability to understand the specific and differentiated nature of small farm production and have promoted some successful programs in the generation and transfer of peasant technology (Altieri and Anderson, 1986).

A large portion of these NGOs are active in the search for alternative systems of production aimed at: (1)improving the production of basic foods at the farm level to enhance the family nutritional intake; (2) promoting an efficient use of local resources (i.e. land, labor, agricultural sub-products, etc.); (3) increasing crop and animal diversity to minimize risks; (4) improving the natural resource base through water, soil and local germplasm conservation; (5) reducing the use of external inputs to reduce dependency, but sustaining yields with appropriate technologies; (6) ensuring that alternative systems have an overall beneficial effect not only on individual families, but on the entire community.

Research conducted by NGOs is reinforced by popular education programs and information dissemination aimed at developing the peasants' own knowl- 
edge and technologies in the realm of health, agricultural production and social organization. Many agricultural programs of certain NGOs tend to preserve and strengthen "peasant's productive rationale" while supporting peasants in the process of technological adaptation and linkage to markets. Most groups contribute to existing technologies through demonstration farms that incorporate both traditional peasant techniques as well as new viable alternatives.

Although some of the efforts of certain NGOs have had considerable impact in promoting grassroots development at the local level, most NGOs understand that rural development strategies will not fully succeed at a more regional level, unless the structural obstacles that cause rural poverty (low productivity and limited access to land) can be overcome.

\section{CONCLUSIONS}

In the ICs, concern about economic problems of overproduction and the environmental consequences of chemical technology has motivated a shift toward a low-input agriculture. The focus is mainly centered around the issue of securing sufficient production but at a lower cost, with less risk and with less pollution. So far, the technologies that have been promoted, with potential to reach these goals, are those that do not threaten the basic tenets of a capitalintensive agriculture. So even if in a particular region it were ecologically desirable to regionalize agricultural production so that agricultural waste products (i.e. manure, crop residues, etc.) could be efficiently recycled between farms and/or between cities and farms, such plans could not be implemented if they required radical changes in land distribution, farm diversification, consumption patterns or waste disposal regulations. Because of this, in many areas of California today, agricultural waste products have become a liability, rather than a resource, and farms that would complement each other in terms of resource utilization and recycling, remain geographically remote from each other. Within this scenario technology, no matter how environmentally sound, can only continue to benefit those large scale and corporate farmers that hold political control over capital, land, labor and other resources.

In the LDCs, history shows that increases in agricultural productivity, whether through sustainable technologies or not, cannot solve the problems of rural poverty (de Janvry, 1981). Current efforts aimed at soil and water conservation, improved food security, germplasm conservation, etc. will serve to counteract hunger or loss of resources temporarily. NGO programs also contribute to improve peasants' technical capabilities so that they can attain greater autonomy in meeting their basic needs and increasing their bargaining power with the state, industry and/or other groups. However, ultimate sustainability will be reached as farmers: (1) increase their access to land, resources and a suitable technology that allows them to manage these resources ecologically; (2) become socially organized to secure governance of resources, equity of ac- 
cess and benefits of markets, inputs and products and income derived from harvests.

Whether or not world leaders face the problem of agricultural sustainability as a political issue, the question of technological development remains a vital one. In this context, agroecology can be useful to guide the process by "screening out" the use of science to achieve political ends, thus destroying the "myth" that all low-input technologies will equally serve sustainable agriculture. Socially equitable technologies promoted by agroecology must have at least four main characteristics.

(1) They must be socially activating by requiring a high level of popular participation, prompting farmers to become a strong political constituency capable of challenging agricultural research and development agenda, and forging their own development path.

(2) They must be culturally compatible not by questioning farmers' rationale, but by actually building upon traditional farming knowledge and combining it with the elements of modern agricultural science.

(3) They must be ecologically sound, not by attempting to modify or transform the ecosystem radically, but rather by identifying management elements that, once incorporated, lead to optimization of the production unit. In this case agricultural diversification directed at serving the basic needs of a family, community, region or nation, becomes a priority over production guided solely by profit motivation.

(4) Agroecological approaches must also be economically viable by minimizing the costs of production through enhancement of the use efficiency of locally available resources, thus decreasing farmers' dependency on the state and industry.

Agroecologists must continue their multidisciplinary research and training efforts so that we understand the complex factors governing agricultural sustainability more fully. This scientific understanding must be guided by a broader understanding; that of the relationship between political institutions, social classes and the scientific community (Jennings, 1988). The insistence on a purely technological focus, even if the promoted technologies are "sustainable", will further obscure recognition of the fundamental problems that make agriculture not sustainable in the first place.

\section{REFERENCES}

Altieri, M.A., 1987. Agroecology: The Scientific Basis of Alternative Agriculture. Westview Press, Boulder, CO, $227 \mathrm{pp}$.

Altieri, M.A. and Letourneau, D.K., 1982. Vegetation management and biological control in agroecosystems. Crop Protect., 1: 405-430.

Altieri, M.A. and Anderson, M.K., 1986. An ecological basis for the development of alternative agricultural systems for small farmers in the Third World. Am. J. Alternative Agric., 1: 30-38. 
Chambers, R. and Ghildyal, B.P., 1985. Agricultural research for resource-poor farmers: the farmer first and last model. Agric. Adm., 20: 1-30.

Conway, G.R., 1986. Agroecosystem Analysis for Research and Development. Winrock International Institute, Bangkok, $111 \mathrm{pp}$.

de Janvry, A., 1981. The Agrarian Question and Reformism in Latin America. Johns Hopkins University Press, Baltimore MD, $311 \mathrm{pp}$.

de Janvry, A., Runstem, D. and Sadoulet, E., 1987. Technological innovations in Latin American agriculture. IICA Program Paper Series, San José, Costa Rica, 126 pp.

Douglass, G.K., 1984. Agricultural Sustainability in a Changing World Order. Westview Press, Boulder, CO, $282 \mathrm{pp}$.

Hobbelink, H., 1987. Biotechnology and Third World Agriculture: New Hope or False Promise? International Coalition for Development Action, Brussels, $57 \mathrm{pp}$.

Jennings, B.H., 1988. Foundations of International Agricultural Research: Science and Politics in Mexican Agriculture. Westview Press, Boulder, CO, 193 pp.

Levins, R., 1973. Fundamental and applied research in agriculture. Science, 181: 523-524.

Lowrance, R., Stinner, B.R. and House, G.J., 1984. Agricultural Ecosystems. Wiley Interscience, New York, NY, 233 pp.

Metcalf, R.L. and Luckman, W.H., 1975. Introduction to Insect Pest Management. Wiley Interscience, New York, NY, 587 pp.

Ortega, E., 1986. Peasant agriculture in Latin America and the Caribbean. Joint ECLAC/FAO, Agriculture Division, Santiago, Chile, 145 pp.

Pimentel, D. and Pimentel, M., 1974. Food, Energy and Society. Edward Arnold, London, 137 pp.

Pimentel, D. and Goodman, N., 1978. Ecological basis for the management of insect populations. Oikos, 30: 422-437.

Price, P.W. and Waldbauer, G.P., 1975. Ecological aspects of pest management. In: R.L. Metcalf and W.H. Luckman (Editors), Introduction to Insect Pest Management. Wiley Interscience, New York, NY, pp. 37-73.

Rabb, R.L. and Guthrie, F.E., 1970. Concepts of Pest Management. North Carolina State University, Raleigh, NC, 242 pp.

Richards, P., 1985. Indigenous Agricultural Revolution. Westview Press, Boulder, CO, 189 pp.

Southwood, T.R.E. and Way, M.J., 1970. Ecological background to pest management. In: R.L. Rabb and F.E. Guthrie (Editors), Concepts of Pest Management. North Carolina State University, Raleigh, NC, pp. 6-28.

Toledo, V.M., Carabias, J., Mapes, C. and Toledo, C., 1985. Ecologia y autosuficiencia alimentaria. Siglo Veintiuno, Mexico, $118 \mathrm{pp}$.

USDA, 1980. Report and Recommendations on Organic Farming. USDA, Washington, DC, 94 pp. van den Bosch, R., 1980. The Pesticide Conspiracy. Anchor Press/Doubleday, New York, NY, 212 pp.

Wolf, E.C., 1986. Beyond the Green Revolution: new approaches for Third World agriculture. World Watch Paper 73, World Watch Institute, Washington, DC, pp. 14-22. 